\title{
Urology in Spinal Cord Injured Patients
}

\author{
J. J. Wyndaele, M. D. \\ Center for Urodynamics and Reeducation, Department of Urology, State \\ University, Ghent, Belgium
}

Neuro-urology and urodynamics have, during the last 10 years, grown to become a major part of urological management and practice. In this evolution, the spinal cord injured patient has often been the model for the development of investigation techniques, methodology and treatment. The growing understanding of what is happening in the lower urinary tract of spinal men, made the management of the bladder dysfunction in these patients more accurate. As a direct result of this, urinary complications have become less frequent and urological pathology is no longer the most important cause of death after spinal cord injury. Although this must be a reason for contentment, one should be aware that this result was only obtained by very high standards of treatment, and by an intensive longterm follow-up. Without a doubt any lapse in management would soon lead to new disasters. Indeed, today we are no nearer to the solution of producing neurological recovery: the dysfunction of the lower urinary tract continues to be one of the most hazardous of neurological deficits seen after spinal cord injury and its possible disturbance of renal function is still directly life-threatening.

The actual urological management can be considered in three distinct periods: a period of bladder drainage in the acute post-injury phase when the lower urinary tract has no active function because of spinal shock; the period of bladder re-education when a new and safe way of regular bladder emptying has to be obtained; the urological follow-up which has to be thorough and lifelong. Treatment of urological complications may be necessary in each of these periods.

The value of intermittent catheterisation in the period of spinal shock has been well documented. Without a doubt this method is the best one, as it leaves the bladder without foreign material, provides its regular complete emptying and results in very few complications if properly performed. In the context of comprehensive management in a spinal unit, the non-touch technique done by a catheter team, will most certainly give a maximum of guarantee for the bladder wall to remain in a favourable condition while awaiting its activity to restart (Bedbrook 1981). Recently a renewed interest has been shown in fine bore suprapubic cystostomy. This method has proved to be useful and safe in the first few days post-injury when extensive fluctuations of diuresis are seen which could lead to bladder overdistention between consecutive catheterisations.

As soon as patients recover from spinal shock, a thorough evaluation of the lower urinary tract function has to be done. In those with a complete spinal lesion, the value of a clinical neurological investigation is still very important. 
The clinical findings correlate well with most findings resulting from technical urodynamic investigations in at least $80 \%$ of patients (Wyndaele, 1984). The great value of technical urodynamic investigations is well known (Rossier and Fam 1979). Nowhere in the field of neuro-urology has urodynamics proved to be more useful, not only in the study of the resolution of spinal shock, but also in defining which type of bladder rehabilitation is best for each individual patient, and for the objective evaluation of a given treatment.

The use of extensive equipment can be of great advantage and subtle investigations are often necessary to make a complete evaluation in specific cases (Madersbacher and Dietl 1984). For routine evaluations, a well trained and experienced investigator will get a wealth of information from a urodynamic study done with a one or two channel cystometer and with EMG of the urethral sphincter. The combination of radioscopy or ultrasound and urodynamics has proved to be most useful in the evaluation of bladder neck function and in the search for vesico-ureteral reflux.

Many therapeutic possibilities exist to obtain a balanced bladder function. Which method would be the most appropriate should however not only depend on the findings of the radiological and urodynamic investigations. A multitude of additional considerations must be taken into account before making the ultimate decision: age, sex, level of spinal cord injury, extent of the lesion, social and economic status, and the degree of ambulation. The overriding principles of the urological re-education still are the preservation of renal function, catheter freedom and the avoidance of infection. But as much as possible, attention should also be given to urinary continence, and to social and vocational acceptability and adaptability when defining a new way of bladder management.

Suprapubic tapping in those with upper motor neuron lesions and the Crédé manoeuvre and/or straining in lower motor neuron lesions continue to be the basic retraining methods to restore a regular bladder emptying (Opitz 1984). The best way to perform these techniques in each individual patient can most properly be guided by urodynamic investigations. For the estimation of bladder volume and postmicturition residual urine, bed-side ultrasound has gained great popularity. What is an acceptable amount of residual urine is debateable. Instead of putting forward an absolute figure for the maximum acceptable residual volume, there is now a tendency to compare the residue with the total bladder volume and to take into account if the upper tracts remain normal, and also if patients have no symptomatic infections.

Complete as possible bladder emptying is desirable, and the achievement of low pressure micturition seems most important to avoid upper tract dilatation and/or reflux (an intravesical pressure of $<60-70 \mathrm{~cm} \mathrm{H} 20$ being considered safe).

Pharmacological treatment has proved very useful in bladder management (Wein, 1984). Intermittent self catheterisation has become very popular and good clinical results are experienced in all kinds of neuropathic bladder dysfunction. The long-term results in spinal cord injured patients still have to be evaluated.

Transurethral sphincterotomy and bladder neck surgery (Perkash, 1984) continue to be used in many patients with outflow obstruction. Other operative procedures can be indicated in some patients: bladder denervation procedures, 
bladder augmentation techniques, colposuspension and even very rarely urinary diversion.

If incontinence is present in a patient who can completely empty his acontractile bladder and who has a bladder of normal capacity and normal bladder compliance-the implantation of a urethral sphincter prosthesis can keep the patient dry (Webster and Stephenson, 1984).

General urological surgical treatment has seen great progress in the last few years: urinary stone streatment with extracorporial shock wave therapy, percutaneous litholapaxy, ureteropyeloscopy, antireflux procedures with a very high success rate; one stage urethral surgery for the treatment of urethral strictures and diverticula, and many more. All of these procedures are making urological surgery for complications in spinal cord injured patients safer and more successful.

Some urological problems remain to be solved: urinary tract infections continue to be frequent despite all measures taken to prevent them. Although the localisation techniques and the development of many new antibiotics succeeded in making treatment more successful, the main option still is prevention. For this, the urological management in the initial phase is known to be of paramount importance.

Incontinence and bladder emptying in quadriplegic females are still very large problems (Lindan et al. 1986). The latest developments of external collecting devices will perhaps bring some solution. The further evolution in the use of sacral anterior root stimulators (Brindley et al. 1982) might be of great therapeutic use in the future.

Many more new developments can be expected in the years to come as intensive work is being done by many investigators on several aspects of urological investigation and treatment. It is our hope that these will contribute to continued improvement in management of one of the most hazardous dysfunctions in spinal man.

\section{References}

BEDBROOK G 1981 The care and management of spinal cord injuries. Springer Verlag, New York, pp. 111-14

Brindley GS, Polkey CE, Rushton DN 1982 Sacral anterior root stimulators for bladder control in paraplegia. Paraplegia 20:365-381

LINDAN R, LEFFLER E, BODNER D 1986 Urological problems in the management of quadriplegic women. Poster presented during the IMSOP meeting Oslo, Norway

Madersbacher H, Dietl P 1984 Urodynamic Practice in neuro-urological patients: techniques and clinical value. Paraplegia 22:145-156

OPITZ J 1984 Treatment of voiding dysfunction in spinal cord injured patients: Bladder retraining. In: BARRETT D, WEIN A (eds) Controversies in neuro-urology. Churchill Livingstone, New York, pp. 437-451

PERKASH I. 1984 Treatment of voiding dysfunction in spinal cord injured patients: Surgical In: Barrett D, Wein A (eds) Churchill Livingstone, New York, pp. 425-435

RosSIER A, FAM B 1979 From intermittent catheterisation to catheterfreedom via urodynamics: A tribute to Sir Ludwig Guttmann. Paraplegia 17:73-85

Webster G, STEPHENSON T 1984 Artificial urinary sphincters. In: Mundy A, STEPHENSON T, WEIN A (eds) Urodynamics. Churchill Livingstone, Edinburgh, pp. 373-380

WeIN A 1984 Pharmacology of the bladder and urethra. In: MUNDy A, STEPHENSON T, Wein A (eds) Urodynamics. Churchill Livingstone, Edinburgh, pp. 26-41

WYNDAELE JJ 1984 A critical review of urodynamic investigations in spinal cord injury patients. Paraplegia 22:138-144 